\title{
Use of acute hospital beds does not increase as the population ages: results from a seven year cohort study in Germany
}

\author{
R Busse, C Krauth, F W Schwartz
}

J Epidemiol Community Health 2002;56:289-293

See end of article for authors' affiliations

.....................

Correspondence to:

Dr R Busse, European

Observatory on Health

Care Systems, c/o Escuela

Nacional de Sanidad,

Sinesio Delgado 8, 28029

Madrid, Spain;

rbusse@isciii.es

Accepted for publication 7 September 2001
Objectives: (1) To compare the number of hospital days used by survivors with those by persons in their last, second last, and third last year of life in relation to age; (2) to analyse lifelong hospital utilisation in relation to life expectancy.

Design: Cohort study using a $10 \%$ sample (stratified by age and sex) of persons insured by one sickness fund.

Setting: Germany, 1989-1995.

Subjects: 69847 survivors (with a minimum of three more years to live), 1385 persons in last, 1368 in second last, and 1333 in third last year of life.

Results: The number of days spent in hospital in the last year of life was lowest for the young (24.2 days under age 25) and the old (23.2 days at age 85+) and was greatest at ages 55-64 (40.6 days). The ratio of days to survivors was highest at age 35-44 (31.0) and fell continously thereafter to 4.3 at age $85+$. Similar patterns were seen for hospital days in the second and third year before death, except that peaks were at $35-44$ years (22.5 and 13.7 days respectively). Calculated lifelong number of hospital days increased with age from 54.8 (death at age 20) to 201.0 (age 90). Numbers of hospital days per year of life, averaged over the entire lifespan, were stable at 2.0-2.2 for deaths between age 50 and 90 (and up to 2.7 at age 20).

Conclusions: Lifelong hospital utilisation for persons who die at 50 or later is directly proportional to the number of years lived. These data contradict results from cross sectional studies that suggest an exponential rise in health care costs as longevity increases. They have important implications for projections of future health care expenditure.
$\mathrm{T}$ he belief that health care costs rise steeply with age is considered "common knowledge" by most clinicians, politicians, health care researchers, and lay people alike. Demographic changes leading to an aging population, a consequent rise in chronic diseases, and technological advances are considered by many to form a triad that will make health care costs unbearable in the future. The belief persists despite a growing body of evidence in support of a more complicated picture. The belief is apparently supported by cross sectional data showing a relation between age and (rising) costs.

Fuchs was the first to point to the fact that the relation between age and health care utilisation or costs is biased by the fact that the percentage of people in their last year of life (which costs well above average) is increasing rapidly with age. ${ }^{1}$ He hypothesised that if mortality in all age groups above 65 would be assumed to be constant, health care costs with age would also be constant.

US Medicare data support this assumption. In addition, however, two further things complicate the picture: (1) health care costs for persons in their last year of life reach a maximum at about the age of 70 years and fall with higher age, and (2) health care costs for the group of survivors rise until the age of about 85 , reach a maximum and fall with higher age. ${ }^{2}$ The marginal increase in lifetime costs associated with an additional year of life decreases as the age at death rises. ${ }^{3}$ However, Medicare data have several drawbacks. Firstly, they are limited to over 65 year olds, which has two important shortcomings: (1) "lifetime costs" are actually costs for the lifespan beyond that age only, and (2) the apparent expenditure peak at 70 years is very close to the lower end of the age spectrum, which makes it difficult to tell whether this is really the maximum (or whether younger deceased incur even higher costs). Secondly, the system of health care financing and provision in the USA has many characteristics, including a complex set of incentives, which limit its generalisability to Europe. Such studies are, however, only possible in certain settings, where linked data encompassing both mortality and hospitalisation are available.

Internationally, the authors are aware of only three longitudinal studies that include persons under the age of 65 years, ${ }^{4-6}$ two of them limited to persons above $45 .{ }^{45}$ One further study from Switzerland included a limited number of decedents below 65 years but did not specify their age. ${ }^{7}$

Concentrating on acute (including psychiatric) hospital utilisation as the largest share of total health care costs, this study had therefore three main objectives

(1) to compare the number of days spent in hospital by survivors in all age groups with those for persons of the same age in their final, second and third last year of life in order to see whether the maximum number of hospital days for decedents is, as US data suggest, around 70 or in fact earlier,

(2) to analyse whether the data found in a health system that is very different from the US system are comparable to the US data for the over 65 year olds, and

(3) to calculate lifelong hospital utilisation in relation to age at death or life expectancy respectively.

\section{METHODS}

The study is based on a $10 \%$ cohort of all insured persons of one German sickness fund which was drawn on 4 November 
Table 1 Number of persons included in study

\begin{tabular}{lllll}
\hline Age $(y)$ & Survivors (male/ female) & $\begin{array}{l}\text { Persons in their } \\
\text { 3rd last year of life } \\
\text { (male/ female) }\end{array}$ & $\begin{array}{l}\text { Persons in their } \\
\text { 2nd last year of life } \\
\text { (male/ female) }\end{array}$ & $\begin{array}{l}\text { Persons in their } \\
\text { last year of life } \\
\text { (male/ female) }\end{array}$ \\
\hline-24 & $22271(12776 / 9495)$ & $28(23 / 5)$ & $28(23 / 5)$ & $25(20 / 5)$ \\
$25-34$ & $15919(11619 / 4300)$ & $40(30 / 10)$ & $49(38 / 1)$ & $52(42 / 10)$ \\
$35-44$ & $11927(8599 / 3328)$ & $88(75 / 13)$ & $85(73 / 12)$ & $89(78 / 11)$ \\
$45-54$ & $9685(6872 / 2813)$ & $147(118 / 29)$ & $261(221 / 40)$ & $138(109 / 29)$ \\
$55-64$ & $6149(4205 / 1944)$ & $269(229 / 40)$ & $346(251 / 95)$ & $33(216 / 41)$ \\
$65-74$ & $2956(1657 / 1299)$ & $333(238 / 95)$ & $323(172 / 151)$ & $323(169 / 154)$ \\
$75-84$ & $838(372 / 466)$ & $326(171 / 155)$ & $134(65 / 69)$ & $171(91 / 80)$ \\
$85+$ & $102(41 / 61)$ & $102(46 / 56)$ & $1368(957 / 411)$ & $1385(969 / 416)$ \\
Total & $69847(46141 / 23706)$ & $1333(930 / 403)$ & &
\end{tabular}

1991. Random samples were taken for 38 age-sex combinations (with age in five year bands and $90+$ years being the highest). The total cohort included 87109 persons.

The dataset includes sociodemographic data (date of birth, sex, date of death), work related data (such as profession, type of employer, sick days, (early) retirement), administrative data (beginning of membership in sickness fund, membership status - that is, member, spouse, child, date and reason for end of membership), and data concerning certain health care utilisations (except for ambulatory services and pharmaceuticals) and diagnoses.

Available data on hospital utilisation included day of admission, day of discharge, and main diagnosis at discharge (coded using ICD-9). No data were available for the type of hospital (for example, large versus small, teaching versus non-teaching), the department or ward (for example, general versus intensive care), individual procedures during the hospital stays or per diem charges. Stays in institutions other than acute general and psychiatric hospitals were either excluded from the calculations (for example, rehabilitative institutions) or were not part of the dataset (for example, stays in nursing homes as they are not covered by sickness funds).

Data were available retrospectively from 1 January 1989, or from birth or entry into the fund if they were after that date. Records were updated in June 1993, and again in December 1995, so that data were available until the end of November 1995.

Altogether 1395 persons died between November 1991 and November 1995. Data for the complete last year, two last years, and three last years of life were available for 1385, 1368, and 1333 respectively to form the groups on which calculations are based. A total of 69847 were continuously insured throughout the period and alive on 30 November 1995. To ensure that they were at least three years away from death, their hospital utilisation between 1 December 1991 and 30 November 1992, was used for the calculations. Altogether 17867 persons were excluded because they left the sickness fund or were not continuously insured for the complete period.

The breakdown of the four groups according to age and sex is given in table 1. In that table, "age" is age at death for persons in their last year of life, for persons in their second last year it is that one year prior to death, and for persons in their third last year it is that two years before death. Age for survivors is that on 1 July 1992. While age was available as a continuous variable, persons were grouped into 10 year age brackets to detect any internal maximums in hospital utilisation.

Cumulative number of hospital days over eight (virtual) lifespans from 20 to 90 years were calculated by assuming that a person consumes hospital days as a "survivor" until three years before death (that is, until 17 if a person dies at 20 or until 87 if he or she dies at 90) and then consumes hospital days as in the third, second, and last year of life. The virtual life concept implies the assumption that the total lifespan is lived in the circumstances of Germany as in the first half of the 1990s. Besides data limitations, this concept was chosen as it is seems likely that actual hospital days in, for example, 1935 would have been more influenced by the health care structures and processes of that time than by the age of, for example, 30 in the case of a person dying in 1995 at 90 years of age-that is, the virtual lifespan concept tries to eliminate all influences on hospital utilisation with the exception of age.

The average number of hospital days per year of life was calculated by dividing those cumulative number of hospital days by the number of years lived.

\section{RESULTS}

\section{Hospital days per year}

The average number of hospital days for persons in their final year of life increased from 24.2 days ( -24 years) to a peak of 40.6 days in 55-64 year-olds. Above that age, the average number fell continuously to 23.2 days ( $85+$ years). For survivors, the number increased steadily. The ratio of hospital days for those in the last year of life compared with survivors was around 30 at ages up to 44 years and fell continuously thereafter to 4.3 at $85+$ years. Utilisation curves for persons in their second and third last year peaked at 35-44 years. Ratios of hospital days of deceased to survivors were much higher for young decedents in the last, second last, and third last year of life (table 2).

\section{Admission to hospital}

In every age group, at least $50 \%$ of persons in their last year of life were admitted to hospital at least once. Young decedents had generally the lowest rates. At around $80 \%$, the rate was highest between 55 and 84 years of age while it dropped to $70 \%$ above that age. Percentages in the second and third last year of life were about one half and one third as high in all age groups. Admission rates for survivors increased continuously with age, however. Again, ratios of deceased to survivors were highest for young decedents (table 3).

\section{Length of stay}

Persons with any hospital stays in their last year of life spent between 30 and 60 days there with the shortest total stays in the oldest age groups. Similarly, younger decedents were treated longer than older decedents in their second and third last year of life. Like admission rates, treatment duration for survivors increased continuously with age. Ratios of deceased to survivors were again higher for younger deceased and approached 1 with increasing age (table 4 ).

Of the two factors influencing the average number of hospital days, the admission rate to hospital had a larger impact than length of stay in the last two years of life. In the third last year, total length of stay was, however, the main determinant of hospital utilisation of younger decedents (tables 3 and 4). 
Table 2 Average number of hospital days/year according to status

\begin{tabular}{|c|c|c|c|c|c|c|c|}
\hline \multirow[b]{2}{*}{ Age $(y)$} & \multirow{2}{*}{$\begin{array}{l}\text { Survivors } \\
\text { days }\end{array}$} & \multicolumn{2}{|c|}{ Persons in their 3rd last year of life } & \multicolumn{2}{|c|}{ Persons in their 2nd last year of life } & \multicolumn{2}{|c|}{ Persons in their last year of life } \\
\hline & & days & ratio to survivors & days & ratio to survivors & days & ratio to survivors \\
\hline-24 & 0.8 & 9.3 & 11.6 & 11.2 & 14.0 & 24.2 & 29.2 \\
\hline $25-34$ & 0.9 & 13.4 & 14.9 & 12.0 & 13.3 & 28.6 & 30.8 \\
\hline $35-44$ & 1.1 & 13.7 & 12.5 & 22.5 & 20.5 & 34.7 & 31.0 \\
\hline $45-54$ & 1.9 & 11.0 & 5.8 & 15.5 & 8.2 & 39.2 & 21.1 \\
\hline $55-64$ & 2.3 & 6.9 & 3.0 & 12.4 & 5.4 & 40.6 & 17.6 \\
\hline $65-74$ & 3.0 & 9.0 & 3.0 & 12.4 & 4.1 & 36.4 & 12.0 \\
\hline $75-84$ & 4.8 & 8.5 & 1.8 & 11.4 & 2.4 & 31.8 & 6.6 \\
\hline $85+$ & 5.4 & 5.1 & 0.9 & 6.3 & 1.2 & 23.2 & 4.3 \\
\hline
\end{tabular}

Table 3 Percentage of persons admitted to hospital at least once/ year according to status

\begin{tabular}{|c|c|c|c|c|c|c|c|}
\hline \multirow[b]{2}{*}{ Age (y) } & \multirow{2}{*}{$\begin{array}{l}\text { Survivors } \\
\%\end{array}$} & \multicolumn{2}{|c|}{ Persons in their 3rd last year of life } & \multicolumn{2}{|c|}{ Persons in their 2 nd last year of life } & \multicolumn{2}{|c|}{ Persons in their last year of life } \\
\hline & & $\%$ & ratio to survivors & $\%$ & ratio to survivors & $\%$ & ratio to survivors \\
\hline-24 & 7.7 & 17.9 & 2.3 & 32.1 & 4.2 & 56.0 & 7.3 \\
\hline $25-34$ & 7.5 & 25.0 & 3.3 & 28.6 & 3.8 & 50.0 & 6.7 \\
\hline $35-44$ & 7.7 & 34.1 & 4.4 & 30.6 & 4.0 & 59.6 & 7.7 \\
\hline $45-54$ & 10.2 & 24.5 & 2.4 & 38.0 & 3.7 & 74.6 & 7.3 \\
\hline $55-64$ & 12.5 & 28.3 & 2.3 & 35.2 & 2.8 & 80.2 & 6.4 \\
\hline $65-74$ & 14.9 & 30.6 & 2.1 & 39.3 & 2.6 & 81.2 & 5.4 \\
\hline $75-84$ & 20.2 & 34.0 & 1.7 & 37.5 & 1.9 & 82.4 & 4.1 \\
\hline $85+$ & 20.6 & 21.6 & 1.0 & 27.6 & 1.3 & 70.2 & 3.4 \\
\hline
\end{tabular}

Table 4 Number of hospital days/year of persons admitted to hospital at least once according to status

\begin{tabular}{|c|c|c|c|c|c|c|c|}
\hline \multirow[b]{2}{*}{ Age $(y)$} & \multirow{2}{*}{$\begin{array}{l}\text { Survivors } \\
\text { days }\end{array}$} & \multicolumn{2}{|c|}{ Persons in their 3rd last year of life } & \multicolumn{2}{|c|}{ Persons in their 2 nd last year of life } & \multicolumn{2}{|c|}{ Persons in their last year of life } \\
\hline & & days & ratio to survivors & days & ratio to survivors & days & ratio to survivors \\
\hline-24 & 10.8 & 52.1 & 4.8 & 34.8 & 3.2 & 43.3 & 4.0 \\
\hline $25-34$ & 12.4 & 53.7 & 4.3 & 41.9 & 3.4 & 57.2 & 4.6 \\
\hline $35-44$ & 14.5 & 40.3 & 2.8 & 73.6 & 5.1 & 58.3 & 4.0 \\
\hline $45-54$ & 18.3 & 45.0 & 2.5 & 40.7 & 2.2 & 52.5 & 2.9 \\
\hline $55-64$ & 18.5 & 24.4 & 1.3 & 35.1 & 1.9 & 50.6 & 2.7 \\
\hline $65-74$ & 20.3 & 29.4 & 1.4 & 31.7 & 1.6 & 44.8 & 2.2 \\
\hline $75-84$ & 23.8 & 25.1 & 1.1 & 30.3 & 1.3 & 38.6 & 1.6 \\
\hline $85+$ & 26.2 & 23.4 & 0.9 & 22.6 & 0.9 & 33.1 & 1.3 \\
\hline
\end{tabular}

\section{Lifelong hospital utilisation}

Table 5 shows that the lifelong number of hospital days increased steadily from $\mathbf{5 4 . 8}$ for those dying at age 20 to 201.0 for those dying at age 90 . The number of hospital days before the last years of life increased by about 10 days for every 10 years lived for persons dying at or before 50 while the increase was more than 30 days for every additional 10 years of life for decedents after age 70. This increase was, however, to a large extent compensated as persons dying at 40 used twice as many hospital resources in their last three years of life as those dying at 90 ( 70.9 and 34.6 days, respectively).

The average numbers of hospital days per year of life were therefore stable at 2.0 to 2.2 for persons dying between ages 50 and 90 while they were higher for persons dying at younger ages: up to 2.7 at age 20 (table 5).

\section{DISCUSSION}

We conclude that the relation between health care costs and age is not as simple as "common knowledge" suggests. The most costly patients are those who die young: If only the last year of life is counted, the 45-64 year-olds have the highest number of hospital days; if the last three years are taken into account, the $35-44$ year-olds accumulate the highest hospital utilisation. If the ratio of hospital days for deceased persons versus survivors of the same age is used as a criterion, persons up to 44 years of age are most expensive.

These results are generally in line with previous studies done in the USA, Canada, and the Netherlands: regarding hospital utilisation in the last year(s) of life in relation to age at death, these studies show maximums in age groups below $65,{ }^{6} 65-74,{ }^{8} 70-74,{ }^{9}$ and $75-84 .{ }^{45}{ }^{10}$ As far the ratio of hospital days of deceased to survivors is concerned, maximums are always in the youngest age groups included in the studies. ${ }^{4689}$ Only data from one study from the UK provide a very different picture with hospital days in the last year of life increasing progressively with age or at least to age 85-89. ${ }^{11}$ The median of hospital days in this study is comparatively low for age groups up to about 75 years in international comparison but the rate of hospital admissions is not particularly low. Therefore, the shorter length of stay in the UK has apparently affected the younger age groups more than the older ones.

The age span covered by our study is, however, considerably wider than all these previous studies, which, except for the Dutch one, ${ }^{6}$ excluded persons below age 45 or-mostly- 65 . Other problems complicating direct comparisons result from the fact that partly the units of measurement are different 
Table 5 Number of hospital days over total (virtual) life span and average number of hospital days per year of life lived according to age at death

\begin{tabular}{|c|c|c|c|c|c|c|c|c|}
\hline & \multicolumn{8}{|c|}{ Person dying at the age of ... } \\
\hline & 20 & 30 & 40 & 50 & 60 & 70 & 80 & 90 \\
\hline $\begin{array}{l}\text { Hospital days before last } \\
\text { three years of life }\end{array}$ & $10.1(18)$ & $20.2(27)$ & $30.0(30)$ & $42.4(39)$ & $62.2(51)$ & $86.2(60)$ & 120.9 (70) & $166.4(83)$ \\
\hline Days in 3rd last year & $9.3(17)$ & $13.4(18)$ & 13.7 (14) & $11.0(10)$ & $6.9(6)$ & $9.0(6)$ & $8.5(5)$ & $5.1(3)$ \\
\hline Days in 2 nd last year & $11.2(20)$ & $12.0(16)$ & $22.5(22)$ & 15.5 (14) & 12.4 (10) & $12.4(9)$ & $11.4(7)$ & $6.3(3)$ \\
\hline Days in last year & $24.2(44)$ & 28.6 (39) & 34.7 (34) & $39.2(36)$ & 40.6 (33) & $36.4(25)$ & 31.8 (18) & $23.2(12)$ \\
\hline Total & $54.8(100)$ & $74.2(100)$ & $100.9(100)$ & $108.1(100)$ & $122.1(100)$ & $144.0(100)$ & $172.6(100)$ & $201.0(100)$ \\
\hline $\begin{array}{l}\text { Average number of days } \\
\text { per year of life }\end{array}$ & 2.7 & 2.5 & 2.5 & 2.2 & 2.0 & 2.1 & 2.2 & 2.2 \\
\hline
\end{tabular}

\section{Key points}

- The correlation between age and hospital utilisation is com plex as the percentage of dying persons with high numbers of hospital days increases with age.

- However, persons who die young "consume" more hospital days in their last years of life than those who die older.

- According to these German data, lifelong hospital utilisation is directly proportional to the number of years lived.

- An aging population might therefore have less impact on health care costs than generally expected.

- While this study expands our knowledge based on previous studies, further confirmation is needed from other countries and health care systems.

(that is, expenditure versus days) and the time of the studies varies from the mid-1970s to the late 1980s. The latter aspect is relevant as studies with two different sets of cross sectional data show that the peak in hospital days for persons in their last year of life has shifted to younger age groups: In British Columbia, 75-79 year-olds had higher number of hospital days than 65-69 year-olds in 1988, but the opposite was true in $1995 .{ }^{13}$ In the USA, the number of hospital days in the last year of life for 65-84 year-old men increased by $6 \%$ between 1986 and 1993, but decreased by $12 \%$ for those 85 and older. ${ }^{14}$

We extended our analysis to a calculation to lifelong hospital utilisation. To do this, we constructed "virtual" lifespans with the available data, which implies several limitations and assumptions. A limitation is the fact that we do not have longitudinal datasets over several decades - that is we cannot calculate the real correlation between utilisation early in life and near death. An assumption is, as already mentioned, that limit us to the German health care structures and utilisation patterns of the first half of the 1990s. An indicator of how time dependent such calculations are is the fact that the average number of hospital days for the whole population decreased from 2.4 in 1993 - that is, at the time of our study, to 2.1 in 1998. ${ }^{15}$

According to our calculations, the number of annual hospital days for persons who die at 50 or later is directly proportional to the number of years lived. These data contradict results from cross sectional studies that suggest an exponential rise in health care costs as longevity increases. Quite in contrast, our data provide evidence that persons dying at an age below 50 are "consuming" above average numbers of hospital days per year of life. In addition, given the high number of hospital days in the last years for younger decedents (which most probably extend beyond the three years documented in the study), our data are most likely to underestimate the average number per year of life in these age groups.

The data provide evidence for shorter periods of morbidity before deaths in older ages than in younger ages; this is especially true if the second and third last year are taken into

account. This may be a hint towards a "compression of morbidity" with rising life expectancy ${ }^{16}$-at least for morbidity leading to hospital treatment. Especially the rather high and long hospital utilisation figures for young decedents are a surprising result that hitherto could not be documented as all other studies included only persons above 45-or even 65-years. These patterns suggest that hospital utilisation is determined by the minority of chronically ill to a much larger degree than expected given that injuries are the leading cause of death in young people.

Two important caveats have to be finally mentioned: hospital care costs are only a part of total health care expenditure and results might be different in other countries. For the USA, Scitovsky has pointed out that nursing care costs in the last year of life are rising with age and this rise almost compensates falling hospital care costs ${ }^{9}$; this has recently also been demonstrated in a study based on data from British Columbia. ${ }^{13}$ Other authors report largely uniform times of lifetime nursing home use regardless of age. ${ }^{17}$ Ambulatory care seems to follow hospital utilisation patterns, however, ${ }^{918}$ but no data over total lifespans are available as of now. A Swiss study included all expenditures reimbursed by two health insurers; in their regression analysis, the authors demonstrate that health care costs are not associated with age but only with proximity to death.

If our main results are confirmed in other current or future studies - that is, if the trend is similar across various cultures and health care systems-our data would have even more important implications for projections of future health care expenditure.

\section{ACKNOWLEDGEMENTS}

The authors wish to thank the sickness fund "Schwäbisch Gmünder Ersatzkasse" for supplying the cohort data. In addition, they acknowledge the support of Hans Dörning, Werner Hofmann and Paolino Piccolo for their contributions to various parts of the project.

\section{Authors' affiliations}

R Busse, C Krauth, F W Schwartz, Department of Epidemiology, Social Medicine and Health System Research and North German Centre for Public Health Research, Medizinische Hochschule Hanover, Germany

\section{REFERENCES}

1 Fuchs VR. "Though much is taken": reflections on aging, health, and medical care. Milbank Mem Fund Q Health Soc 1984:62:143-66.

2 Lubitz JD, Riley GF. Trends in Medicare payments in the last year of life. N Engl J Med 1993;328: 1092-6.

3 Lubitz J, Beebe J, Baker C. Longevity and Medicare expenditures. N Engl J Med 1995;332:999-1003.

4 Roos NP, Montgomery P, Roos LL. Health care utilization in the years prior to death. Milbank Q 1987;65:231-54.

5 Scitovsky AA. Medical care in the last twelve months of life: the relation between age, functional status, and medical care expenditures. Milbank Q 1988;66:640-60.

6 van Vliet RCJA, Lamers LM. The high costs of death: should health plans get higher payments when members die? Med Care 1998;36:1451-60. 
7 Zweifel P, Felder S, Meiers M. Ageing of population and health care expenditure: a red herring? Health Econ 1999;8:485-96.

8 Lubitz J, Prihoda R. The use of Medicare services in the last 2 years of life. Health Care Financ Rev 1984;5:117-31.

9 Scitovsky AA. "The high cost of dying" revisited. Milbank $Q$ 1994;72:561-91.

10 Temkin-Greener $\mathbf{H}$, Meiners MR, Petty EA, et al. The use and cost of health services prior to death: a comparison of the Medicare-only and the Medicare-Medicaid elderly populations. Milbank Q 1992;70:679-701.

11 Henderson J, Goldacre M. Griffith M. Hospital care for the elderly in the final year of life: a population based study. BM 1990;301:17-19.

12 Himsworth RL, Goldacre M. Does time spent in hospital in the final years of life increase with age at death? A population based study. BM 1999:319:1338-9.
13 McGrail K, Green B, Barer ML, et al. Age, costs of acute and long term care and proximity to death: evidence for $1987 / 88$ and 1994/95 in British Columbia. Age Ageing 2000;29:249-53.

14 Liao Y, McGee DL, Cao G, et al. Quality of the last year of life of older adults: 1986 vs 1993. JAMA 2000;283:512-18.

15 Busse R. Health care systems in transition - Germany. Copenhagen: European Observatory on Health Care Systems, 2000.

16 Fries JF. Aging, natural death, and the compression of morbidity. N Engl J Med 1980;303:130-5.

17 Murtaugh CM, Kemper P, Spillman BC, et al. The amount, distribution, and timing of lifetime nursing home use. Med Care 1997;35:204-18.

18 Roos NP, Shapiro E, Tate R. Does a small minority of elderly account for a majority of health care expenditures? A sixteen-year perspective. Milbank Q 1989:67:347-6.

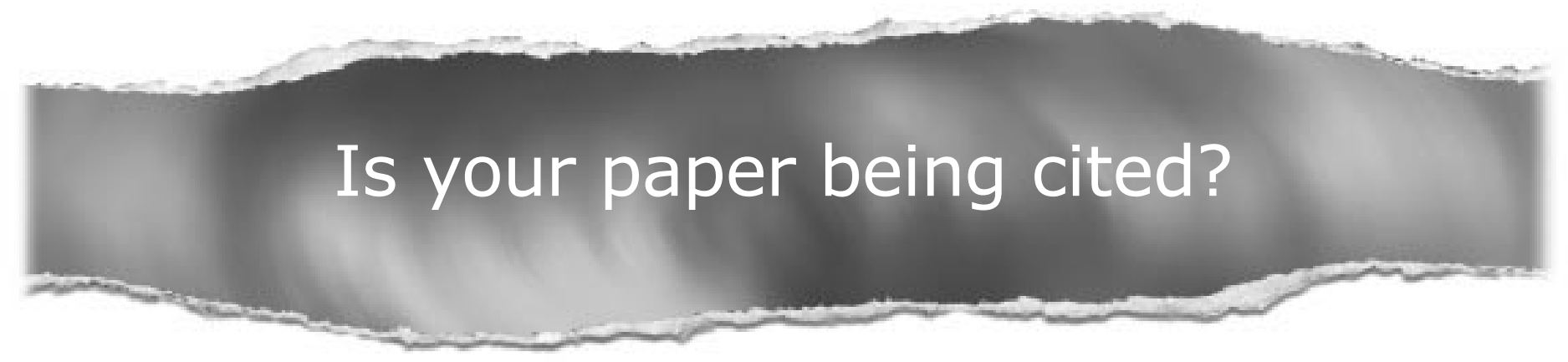

\section{CiteTrack service}

CiteTrack will alert you by email whenever new content in the Journal of Epidemiology and Community Health or a participating journal is published that matches criteria you want to track Topics: Tell CiteTrack which words or subjects to watch for in new content Authors: Be alerted whenever key authors you are following publish a new paper Articles: Know whenever a paper of interest to you is referenced by another paper

\section{www.jech.com}

